Marquette University

e-Publications@Marquette

Nursing Faculty Research and Publications

Nursing, College of

$1-1-2016$

Engaging in Culturally Informed Nursing Care with Hmong Children and Their Families

Shoua Xiong

Marquette University

Nora Degroote

Marquette University

Hayley Byington

Marquette University

Jamie Harder

Marquette University

Krystal Kaminski

Marquette University

See next page for additional authors

Accepted version. Journal of Pediatric Nursing, Vol. 31, No. 1 (January/February 2016): 102-106.

DOI. (C) 2016 Elsevier Inc. Used with permission 
Authors

Shoua Xiong, Nora Degroote, Hayley Byington, Jamie Harder, Krystal Kaminski, and Kristin Haglund 


\title{
Engaging in Culturally Informed Nursing Care with Hmong Children and Their Families
}

\author{
Shoua Xiong \\ College of Nursing, Marquette University, \\ Milwaukee, WI \\ Nora Degroote \\ College of Nursing, Marquette University, \\ Milwaukee, WI \\ Hayley Byington \\ College of Nursing, Marquette University, \\ Milwaukee, WI \\ Jamie Harder \\ College of Nursing, Marquette University, \\ Milwaukee, WI \\ Krystal Kaminski \\ College of Nursing, Marquette University, \\ Milwaukee, WI \\ Children's Hospitals \& Clinics of Minnesota, \\ Northeast Pediatric Clinic, \\ Hugo, MN \\ Kristin Haglund \\ College of Nursing, Marquette University, \\ Milwaukee, WI
}


NOT THE PUBLISHED VERSION; this is the author's final, peer-reviewed manuscript. The published version may be accessed by following the link in the citation at the bottom of the page.

The Hmong are an ethnic hill tribe group originally from Southern China with concentrated populations throughout Southeast Asia, especially the mountains of northern Laos. Following the Vietnam War, the Hmong started immigrating to the United States in waves to escape prosecution for fighting communism alongside the United States. Today, the Hmong population in the United States is growing rapidly, with a median age of 20.4 years. As the Hmong move and redistribute themselves across the country to be with family or pursue new opportunities, it is more and more likely that nurses everywhere will interact with Hmong children and their families. Historically medically underserved, the Hmong community continues to face barriers to healthcare as a result of culture, language, and lack of access. Nurses who are informed about cultural values and norms of the Hmong and their family and social structures, as well as their spiritual and traditional practices, will be able to establish trust with their pediatric patients and their caregivers. Utilizing strategies including interpretive services, asking detailed social and physical histories, providing extra appointment time, asking open ended questions, and employing teach back methods can help improve communication as well as provide higher quality care that addresses the specific needs of this population.

Key words: Hmong, Culture, Primary health care, Health services utilization, Attitudes

The Hmong People originated from Southern China and migrated to different parts of Southeast Asia. The Hmong population in the U.S. is from Northern Laos (Centers for Disease Control and Prevention [CDC], 2008). In the 1960s and 1970s the Hmong in Laos were recruited by the U.S. Central Intelligence Agency to fight on the side of the royal Lao government against communist leaders and forces. After Laos fell to the Communist party in 1975, the Hmong experienced severe retaliation for siding with the Americans causing many to flee to refugee camps in Thailand (Tatman, 2004). Overtime, Hmong refugees were repatriated to Laos, remained in Thailand, or were relocated to other countries. Relocation to the U.S. began in the 1980 s and continued into the 2000s with a marked decrease since 2007 (CDC, 2008). Today there are over 260,000 Hmong Americans living in the U.S. representing a 40\% increase since 2000 (Pfeifer, Sullivan, Yang, \& Yang, 2013). Eighty-percent of Hmong-Americans live in California, Minnesota and Wisconsin (Xiong, 2013).

The Hmong population is growing in number and experiencing a diaspora within the U.S. It is more and more likely that nurses across the country will interact with Hmong American children and their families. Thus the purpose of this paper is to provide information that

Journal of Pediatric Nursing, Vol 31, No. 1 (January/February 2016): pg. 102-106. DOI. This article is (C Elsevier (WB Saunders) and permission has been granted for this version to appear in e-Publications@Marquette. Elsevier (WB Saunders) does not grant permission for this article to be further copied/distributed or hosted elsewhere without the express permission from Elsevier (WB Saunders). 
will facilitate sensitive and culturally-informed nursing care, improve communication between nurses and Hmong children and their families and lead to positive health outcomes. Specifically, this paper describes how the Hmong cultural context may influence how children and families understand health, interact with health care providers and manage health problems. It is important to understand that culture is dynamic and changing. In addition, individuals vary how they identify with their ethnic heritage and how they express their cultural identity. Thus this paper is not intended to suggest that all Hmong Americans practice their culture in the same way, rather is it intended to provide practitioners with information regarding salient aspects of Hmong culture to provide a place from which to start a caring relationship.

\section{Cultural Understanding of Health Among Hmong Children and Families}

There are several important aspects of Hmong culture that influence how health is viewed and experienced including social and family structure and cultural and religious beliefs.

\section{Social Structure}

Hmong culture is patriarchal in nature. The Hmong may live in clan societies which include extended family members. Clans, versus individuals or nuclear families, are the basic unit of social and political organization in Hmong culture (Cobb, 2010). There are 18 clans in the Hmong culture each having a designated clan leader, and they are all represented in the United States. The clan leader is a respected older male who is sought out for advice concerning anything from arguments between spouses to healthcare decisions. There is also a spiritual healer, called the shaman, utilized across clans. The shaman's role is to identify the spiritual causes of illness, communicate with the spirit world, and restore wandering souls to the body (Cobb, 2010). In traditional Hmong households, the men along with the shaman make all decisions, even regarding another's health. Healthcare decisions may take more time because patients and their families consult with clan leaders before agreeing to plans or treatments. 
NOT THE PUBLISHED VERSION; this is the author's final, peer-reviewed manuscript. The published version may be accessed by following the link in the citation at the bottom of the page.

\section{Family Structure}

Men and women have distinct roles in families. Marriage is considered a duty, and women are primarily responsible for caring for the children and domestic duties (Cobb, 2010). Commonly Hmong American women marry between the ages of 13 and 23 with many marriages occurring by age 16 (Owens, 2007 and Vang and Her, 2014). Young women often partner with older men as men commonly marry between the ages of 18 and 30 (Bankston, 2015). Some of the marriages are conducted by Hmong presiders and are cultural marriages but are not considered legal marriages in the U.S. (Randolph, 2006). Polygamy is a cultural practice in which men may take several wives and or a mistress; this practice has decreased but continues to occur in the U.S (Bankston, 2015). Newer generations of Hmong Americans may follow U.S. cultural norms such as postponing marriage and child bearing to at least 18 years of age or after completion of higher education, or choosing not to marry. Divorce is also becoming more common among Hmong American couples (Xiong, 2013).

Hmong American families tend to be large and on average include 6.5 members compared to average families in the general U.S. population which include 3.1 people (Xiong, 2013). Children are viewed as treasures, and Hmong homes are child-centered (Bankston, 2015). Typically, births are close together resulting in large families with a narrow range of ages among the children. While Hmong Americans have an equal rate of employment as the general U.S. population, they make less money than other American workers largely because of low education attainment and employment concentration in low-paying jobs (Vang, 2013). Lower incomes contribute to high rates of poverty as evidenced by $25 \%$ of Hmong American families living in poverty compared to $12 \%$ of families in the U.S. population (DeNavas-Walt \& Proctor, 2014). About 15\% of Hmong Americans are uninsured (Pfeifer et al., 2013). Forty-two percent of Hmong Americans utilize public sources of insurance compared to $29 \%$ of the general U.S. population (Pfeifer et al., 2013).

Journal of Pediatric Nursing, Vol 31, No. 1 (January/February 2016): pg. 102-106. DOI. This article is (C Elsevier (WB Saunders) and permission has been granted for this version to appear in e-Publications@Marquette. Elsevier (WB Saunders) does not grant permission for this article to be further copied/distributed or hosted elsewhere without the express permission from Elsevier (WB Saunders). 
NOT THE PUBLISHED VERSION; this is the author's final, peer-reviewed manuscript. The published version may be accessed by following the link in the citation at the bottom of the page.

\section{Cultural and Religious Beliefs}

As a religion, the Hmong practice animism, the belief that spirits live in, on and around the human body. These spirits, according to Hmong health practices, affect health and illness. Young babies are considered to be at the greatest risk for illness and are often blessed with khi tes (string) necklaces or bracelets to protect against evil spirits that could cause illness ( Johnson, 2002). Traditionally, the Hmong also practice Shamanism, which is the belief in the spirit world and its connection to all living things ( Cobb, 2010 and Gerdner, 2012). A balance between the body and the spirit is required for good health. Hmong healers, or shamans, serve to bridge the human world with the spiritual world and resolve issues of illness through ceremonies to bring back the spirits of the ill people (Johnson, 2002). Herbalists also treat illnesses. Illnesses are ascribed to natural and spiritual causes. A natural illness, such as a headache, is viewed as a result of the disharmony between yin and yang, or hot and cold (Lee \& Vang, 2010). Treatment for natural illnesses may consist of bringing a balance to the body through herbal medicine, acupuncture, spoon rubbing, coining or cupping. Spoon rubbing is a process where patients' bodies are repeatedly scraped with a silver spoon. Coining is lightly scraping the skin with a hot coin to cast away evil spirits (Lee \& Vang, 2010). Cupping is creating a vacuum on the skin to draw out tension, fever, or pain. These treatments are not harmful to children although they may cause bruising and can be mistaken for abuse (Dixon \& Stein, 2006). A traditional belief of Shamanism is reincarnation. The body must be whole without deformities in order to be properly reincarnated prompting some families to decline procedures that disrupt the integrity of the body such as surgeries, implants, or dental work (Cobb, 2010).

In the Hmong tradition there was no concept of chronic illness; one was ill and either recovered or died (Johnson, 2002). Chronic diseases, birth defects, and mental illnesses may be viewed as spiritual illnesses and consequences of bad actions from patients' former lives. These spirit-rooted illnesses are often attributed to soul loss, offended spirits or ancestors, or menacing spirits (Carteret, 2012). It can be difficult to help Hmong families manage their children's chronic illnesses following allopathic guidelines. They may 
disagree with the prescribed therapies, for example, that medications need to be taken regularly (i.e. inhaled corticosteroid for asthma). Some Hmong parents may decline allopathic treatments because they believe they are ineffective or that they will upset the spirits more by taking such treatments.

\section{Cultural Influence on Interactions with Health Care Providers}

An area of potential misunderstanding is the use of the word "yes" and nodding one's head. In the U.S. nodding generally means that a person agrees or understands, in Hmong culture it simply means they are listening (Johnson, 2002 and Pinzon-Perez, 2006). Because the Hmong have a high sense of respect for health care providers, they will often say "yes" or nod during a conversation as a sign of respect that they are listening. This may cause a misunderstanding between providers and patients. Providers may believe that the family is indicating agreement with the plan, when the family is simply stating that they are listening, not that they necessarily understand or that they will follow through with the plan of care.

The Hmong may be wary of a health care provider's intentions (Lee \& Vang, 2010). Hmong Americans' distrust of the medical system can stem from unfamiliarity with the healthcare system, negative experiences individuals in the Hmong community have had, and general skepticism of systems in the U.S. due to the betrayal of the Hmong after the Vietnam War (Lee \& Vang, 2010). Distrust can lead to delays in seeking health care and poorer health outcomes. Some Hmong patients may distrust medications when prescribed for conditions that they cannot see, such as hypertension (Cobb, 2010). Some Hmong patients fear and distrust hospitalization as they view hospitals as places where someone goes to die.

Hmong American families do not typically take vitamins or seek routine health or dental care (Nuttall \& Flores, 1997). Reflecting their belief in the importance of body integrity for reincarnation, immunizations are traditionally not accepted. However, most Hmong parents will agree to immunizations once they understand their 
importance to health and that they are required for school and other activities (Carteret, 2012). Still, Hmong children in the U.S. are under immunized (Baker et al., 2010 and Nuttall and Flores, 1997). Parents who patronize shamans and herbalists for health care report increased barriers to getting their children immunized (Baker et al., 2010). Hmong parents who use herbal remedies and advice from shamans may have increased skepticism about the need for, and safety of, immunizations. Also parents utilizing these alternative providers may not establish care with a primary care provider which limits their access to childhood immunizations. Hmong families with low-incomes experience lack of access to immunizations and have lower perceptions of the importance of immunizations (Baker et al., 2010). Language barriers, low incomes, and transportation issues interfere with access to healthcare and immunizations for Hmong children.

\section{Strategies to Facilitate Provision of Care}

Hmong American families may be unfamiliar with health care practices such as immunizations, blood tests, and preventative screenings. Parents may decline recommended interventions or screenings because they do not understand the practices or the need for them. It is important for nurses to routinely explain recommendations including what the intervention or procedure is, what will happen to the patient, why it is needed and what will happen next (Carteret, 2012). Hmong persons are sensitive to signs of actual or perceived disrespect and discrimination that may be conveyed by health care providers (Thorbun, Kue, Keong \& Lo, 2012). Many Hmong Americans speak English as a second language and closely pay attention to nonverbal communication to help them understand the spoken words (Carteret, 2012). It is very important for nurses to be aware of their nonverbal communication to prevent insult and misunderstandings. When Hmong Americans feel disrespected by health care providers, they tend to not confront the providers but choose not to return. They instead seek care from cultural providers or use cultural remedies and return to their previous place of care as a last resort (Thorbun et al., 2012). Conveying respect and providing education without judgment are ways to establish trust with Hmong children and their families.

Journal of Pediatric Nursing, Vol 31, No. 1 (January/February 2016): pg. 102-106. DOI. This article is (C) Elsevier (WB Saunders) and permission has been granted for this version to appear in e-Publications@Marquette. Elsevier (WB Saunders) does not grant permission for this article to be further copied/distributed or hosted elsewhere without the express permission from Elsevier (WB Saunders). 
When caring for Hmong children, particularly adolescents, it is important to assess parent-child relationships and interpersonal conflicts. Consider speaking with adolescents and parents separately. Hmong children are expected obey their parents and to refrain from arguing or verbally challenging them thus expression of conflict may be difficult for parents and teens when they are together (Edinburgh, Garcia, \& Saewyc, 2013). Additionally, traditional Hmong expectations for gender roles are different than mainstream American cultural expectations, and Hmong teens may find them restrictive (Xiong, Detzner \& Cleveland, 2005). The conflicting expectations can be challenging for Hmong children and adolescents as they struggle to maintain their ethnic identify, continue to honor their family and culture and adapt to their new culture.

Another way to build trust with Hmong families is to collaborate with their shaman. In the Central Valley region of California a program has been established in which Hmong shamans (invited by their clan leader) consult with the U.S. health care providers concerning various diagnoses and treatments and collaboratively deliver health care. Shamans go to hospitals to perform healing ceremonies to restore lost souls to the bodies of their ill patients who are also receiving conventional care in a U.S. hospital (Pinzon-Perez, 2006). Hmong patients feel that their spirits are being taken care of, that their clan leaders and shamans support their participation in the allopathic treatment plan and that the U.S. providers respect them and their culture.

Addressing language barriers between patients and health care providers is also a priority. It is important for nurses to assess families' language preferences and written and oral fluency in English and Hmoob which is the native Hmong language. In English, the language is called Hmong. In 2006-2010, 8\% of Hmong-American families spoke only English at home, 49\% were bilingual reporting that they spoke Hmong at home and also spoke English very well, and $42 \%$ spoke Hmong at home and did not have family members who spoke English well (Xiong, 2013). When Hmong is the family's preferred language, interpreter services are necessary. Federal regulations require that health organizations offer and provide language assistance services to patients with limited English proficiency (LEP) at no cost and in a timely manner (Hoffman, 2011). Hmong-speaking patients 
who do not receive interpretative services have been shown to receive poorer quality of care (Cobb, 2010). Institutions without Hmong interpreters on site may provide access to telephone interpreter services. Utilizing family members as interpreters is not a safe or best practice, as studies have demonstrated higher medication errors when bilingual family members or workers are utilized instead of trained staff (Alborn \& McKinney, 2014). It is important to make sure that enough time is allotted for the visit in order for a complete and thorough conversation to take place as translation of healthcare information from English into Hmong may increase the duration of the discussion. Recognizing that parents may nod their heads to show that they are listening rather than they agree, it is important to ask questions and not assume that parents are understanding or agreeing with what is being said. Open ended questions such as "What questions do you have for me?" are important in order to gauge the parents' level of understanding. Utilize a 'teach back' method to demonstrate to the nurse that the child and family understand the cares that they have just learned.

Provide written materials in the preferred language as well. Medline Plus, sponsored by the U.S. Library of Medicine National Institutes of Health, is a source for free education materials written in Hmong http://www.nlm.nih.gov/medlineplus/languages/hmong.html. The Immunization Action Coalition provides free immunization education handouts written in Hmong http://www.immunize.org/handouts/hmong.asp. When written materials are not available, consider involving the patients in developing educational materials (Cobb, 2010). Their involvement will increase the cultural relevancy of the materials, help the families learn the content and also engender feelings of investment in advancing their community's health. The Hmong Health Education Network authored a website called Hmonghealth.org that includes illustrations, health information in English and Hmong, and a health dictionary written in Hmong. This website is maintained by the Wausau (Wisconsin) Area Hmong Mutual Association. A website called "ECHO, Bridging the Communications Gap for Immigrants and Refugees in Minnesota" offers health videos on a wide variety of topics in Hmong, the website can also be viewed with all of the text in the Hmong language http://www.echominnesota.org/hmn/tools/echo-tv/view-allshows.

Journal of Pediatric Nursing, Vol 31, No. 1 (January/February 2016): pg. 102-106. DOI. This article is @ Elsevier (WB Saunders) and permission has been granted for this version to appear in e-Publications@Marquette. Elsevier (WB Saunders) does not grant permission for this article to be further copied/distributed or hosted elsewhere without the express permission from Elsevier (WB Saunders). 
To engender trust, nurses may express cultural awareness, consider children and families within their cultural context, and incorporate Hmong health practices desired by the family into their care (Cobb, 2010). Recommended communication strategies include tempering expressed emotion since raising one's voice may lose the respect of the family; using a quiet, unhurried way of speaking and acting to demonstrate wisdom and good judgment; accepting traditional healing practices of the family so long as they are not harmful to the child; understanding symbols and relations of healing that are meaningful to the Hmong; and encouraging and supporting the use of allopathic medicine and practices in a consistent, nonjudgmental manner (Meyers, 1992). Address Hmong parents formally with Mr., Mrs., or Ms.

Allocate adequate time for visits with new Hmong children to obtain a thorough social history, family history, and health history. Multiple appointments may be needed to obtain a complete history, assess current health issues and create a collaborative plan of care.

The history should include questions about the families' utilization of advice from clan leaders, shamans and herbalists and use of herbs and other cultural remedies. A thorough family health history is important. Even if parents do not know the English name for a condition, describing symptoms or medications taken for the condition can be helpful. Asking about immunizations, especially with new immigrant families, is also important. The Hib, pneumococcal, hepatitis A, rubella, mumps and varicella vaccines may not have been given to new immigrants from Southeast Asia. Hepatitis B, tuberculosis, and HIV screening should be done as these diseases are endemic in Southeast Asia (American Academy of Pediatrics, 2012).

\section{Conclusion}

Cultural informed nursing care includes the acceptance and awareness of cultural differences among groups and recognizing that cultural groups have diverse ways of communicating, behaving, and problem solving (Servonsky \& Gibbons, 2005). To develop cultural competence, it is important that nurses thoughtfully explore their own worldviews, become familiar with core cultural issues especially those related to health and illness, develop skills to effectively communicate 
with children and families from diverse backgrounds, and become knowledgeable about the cultural groups they care for (Burns, Dunn, Brady, Starr, \& Blosser, 2009).

Working with families whose culture is different can be challenging and enjoyable. Being prepared with some cultural information prior to the first encounter will allow nurses to approach Hmong American families with interest and compassion. Recognizing and respecting the importance of culture for Hmong American families is a step toward building a relationship in which nurses and families trust each other and health flourishes.

\section{References}

Alborn and McKinney, 2014. J. Alborn, K. McKinney. Use of and interaction with medical interpreters. American Journal of Health-System

Pharmacy, 71 (2014), pp. 1044-1048

American Academy of Pediatrics, 2012. American Academy of Pediatrics. Immunization in special clinical circumstances. L. Pickering, C. Baker, D. Kimberlin, S. Long (Eds.), Red book: 2012 report of the committee on infectious diseases, American Academy of Pediatrics, Elk Grove Village, IL (2012), pp. 69-109

Baker et al., 2010. D. Baker, M. Dang, M. Ly, R. Diaz. Perception of barriers to immunization among parents of Hmong origin in California. American Journal of Public Health, 100 (2010), pp. 839-845

Bankston, 2015. C. Bankston. Hmong Americans. Retrieved from http://www.everyculture.com/multi/Ha-La/HmongAmericans.html\#ixzz3WAJPRonr (2015)

Burns et al., 2009. C. Burns, A. Dunn, M. Brady, N. Starr, C. Blosser. Pediatric primary care. Saunders Elsevier, St. Louis, MS (2009)

Carteret, 2012. M. Carteret. Providing healthcare to Hmong patients and families. Retrieved from http://www.dimensionsofculture.com/2012/01/providinghealthcare-to-hmong-patients-and-families/ (2012)

Centers for Disease Control and Prevention, 2008. Centers for Disease Control and Prevention. Promoting cultural sensitivity: A practical guide for tuberculosis programs that provide services to Hmong persons from Laos. U.S. Department of Health and Human Services, Atlanta, GA (2008)

Cobb, 2010. T. Cobb. Strategies for providing cultural competent health care for Hmong Americans. Journal of Cultural Diversity, 17 (2010) (79-7983) 
NOT THE PUBLISHED VERSION; this is the author's final, peer-reviewed manuscript. The published version may be

accessed by following the link in the citation at the bottom of the page.

DeNavas-Walt and Proctor, 2014. C. DeNavas-Walt, B. Proctor. Income and poverty in the United States: 2013. U.S. Census Bureau, Current Population Reports, P60-249, U.S. Government Printing Office, Washington, DC (2014)

Dixon and Stein, 2006. S. Dixon, M. Stein. Encounters with children. Mosby Elsevier, Philadelphia, PA (2006)

Edinburgh et al., 2013. L. Edinburgh, C. Garcia, E. Saewyc. It's called "Going out to play": A video diary study of Hmong girls' perspectives on running away. Health Care for Women International, 34 (2013), pp. $150-168$

Gerdner, 2012. L. Gerdner. Shamanism: Indications and use by older Hmong Americans with chronic illness. Hmong Studies Journal, 13 (2012), pp. $1-22$

Hoffman, 2011. N. Hoffman. The requirements for culturally and linguistically appropriate services in health care. Journal of Nursing Law, 14 (2011), pp. 49-57

Johnson, 2002. S. Johnson. Hmong health beliefs and experiences in the western health care system. Journal of Transcultural Nursing, 13 (2002), pp. 126-132

Lee and Vang, 2010. H. Lee, S. Vang. Barriers to cancer screening in Hmong Americans: The influence of health care accessibility, culture, and cancer literacy. Journal of Community Health, 35 (2010), pp. 302-314

Meyers, 1992. C. Meyers. Hmong children and their families: Consideration of cultural influences in assessment. The American Journal of Occupational Therapy, 46 (1992), pp. 737-744

Nuttall and Flores, 1997. P. Nuttall, F. Flores. Hmong healing practices used for common childhood illnesses. Pediatric Nursing, 23 (1997), pp. 247-251

Owens, 2007. C. Owens. Hmong cultural profile. Retrieved from https://ethnomed.org/culture/hmong/hmong-cultural-profile (2007)

Pfeifer et al., 2013. M. Pfeifer, J. Sullivan, K. Yang, W. Yang. Hmong population and demographic trends in the 2010 census and 2010 American community survey. M.E. Pfeifer, B.K. Thao (Eds.), State of the Hmong American community, Hmong National Development, Washington, DC (2013)

Pinzon-Perez, 2006. H. Pinzon-Perez. Health issues for the Hmong population in the U.S.: Implications for health educators. International Electronic Journal of Health Education, 9 (2006), pp. 122-133

Randolph, 2006. T. Randolph. Hmong legislators say cultural marriage bill is unnecessary. Minnesota Public Radio News (2006) (Retrieved from http://www.mprnews.org/story/2006/03/20/hmongmarriage)

Journal of Pediatric Nursing, Vol 31, No. 1 (January/February 2016): pg. 102-106. DOI. This article is (C Elsevier (WB Saunders) and permission has been granted for this version to appear in e-Publications@Marquette. Elsevier (WB Saunders) does not grant permission for this article to be further copied/distributed or hosted elsewhere without the express permission from Elsevier (WB Saunders). 
NOT THE PUBLISHED VERSION; this is the author's final, peer-reviewed manuscript. The published version may be accessed by following the link in the citation at the bottom of the page.

Servonsky and Gibbons, 2005. E. Servonsky, M. Gibbons. Family nursing: Assessment strategies for implementing culturally competent care. Journal of Multicultural Nursing \& Health, 11 (2005), pp. 51-56

Tatman, 2004. A. Tatman. Hmong history, culture, and acculturation: Implications for counseling the Hmong. Journal of Multicultural Counseling and Development, 32 (2004), pp. 222-233

Thorburn et al., 2012 S. Thorburn, J. Kue, K. Keon, P. Lo. Medical Mistrust and Discrimination in Health Care: A Qualitative Study of Hmong Women and Men. Journal of Community Health, 37 (4) (2012), pp. $822-829$

Xiong, 2013. N. Xiong. Households and marital status of Hmong in the United States, 2008-2010. M.E. Pfeifer, B.K. Thao (Eds.), State of the Hmong American Community, Hmong National Development, Washington, DC (2013)

Xiong et al., 2005. Z. Xiong, D. Detzner, M. Cleveland. Southeast Asian adolescents' perceptions of immigration parenting practices. Hmong Studies Journal, 5 (2005), pp. 1-20

Vang, 2013. C. Vang. Hmong socioeconomic trends in the U.S. M.E. Pfeifer, B.K. Thao (Eds.), State of the Hmong American Community, Hmong National Development, Washington, DC (2013)

Vang and Her, 2014. P. Vang, P. Her. Teenage marriage among Hmong American women. Journal of Human Behavior in the Social Environment, 24 (2) (2014), pp. 138-155

Corresponding author: Kristin Haglund, PhD, RN. 